\title{
MELHORAMENTO DO ARROZ: I. COMPORTAMENTO DE CULTIVARES E LINHAGENS DE ARROZ IRRIGADO NO ESTADO DE SÃO PAULO EM 1990/91 E 1991/92 ( ${ }^{1}$ )
}

\author{
LUIZ ERNESTO AZZINI $\left({ }^{2.9}\right)$, CÂNDIDO RICARDO BASTOS $\left({ }^{3,9}\right)$, \\ OMAR VIEIRA VILLELA $\left({ }^{4}\right)$, PAULO BOLLER GALLO $\left({ }^{5}\right)$, \\ MAURO SAKAI $\left({ }^{6}\right)$, JACIRO SOAVE $\left({ }^{7,9}\right)$, \\ LÜCIA HELENA SIGNORI MELO DE CASTRO $\left({ }^{3}\right)$ e OTÁVIO TISSELI FILHO $\left({ }^{8,9}\right)$
}

\begin{abstract}
RESUMO
Testaram-se cultivares e linhagens de arroz irrigado quanto a características agronômicas em diversas localidades paulistas durante os anos agrícolas 1990/91 e 1991/92. O cultivar IAC 101 e a linhagem IAC 1085 apresentaram excelente potencial e estabilidade produtiva, moderada resistência à brusone na folha e na panícula, porte baixo, resistência ao acamamento e bom rendimento de grãos inteiros no beneficiamento. A linhagem IAC 1085 apresentou, também, ciclo de florescimento precoce, constituindo genótipo altamente promissor. Os cultivares IAC 238, IAC 242 e IAC 100 também mostraram bom potencial produtivo, principalmente em 1991/92. O cultivar IAC 4440 mostrou-se altamente suscetível à brusone, tanto nas folhas como nas panículas. As linhagens IAC 1091 e IAC 1231 apresentaram resistência à brusone nas panículas, podendo servir como fontes de genes em futuros programas de melhoramento genético.
\end{abstract}

Termos de indexação: arroz, Oryza sativa $L$., potencial e estabilidade produtiva de cultivares e linhagens, resistência à brusone.

(1) Recebido para publicação em 13 de maio de 1994 e aceito em 7 de julho de 1995.

$\left(^{2}\right)$ Seção de Genética, Instituto Agronômico, Caixa Postal 28, 13001-970 Campinas (SP).

(3) Seção de Arroz e Cereais de Inverno, IAC.

(4) Estação Experimental de Pindamonhangaba, IAC.

(5) Estação Experimental de Mococa, IAC.

${ }^{6}$ ) Estação Experimental de Pariquera-Açu, IAC.

( ${ }^{7}$ Seção de Fitopatologia, IAC.

$\left.{ }^{8}\right)$ Divisão de Estações Experimentais, IAC.

$\left({ }^{9}\right)$ Com bolsa de pesquisa do CNPq. 


\section{ABSTRACT \\ RICE BREEDING: I. PERFORMANCE OF CULTIVARS AND LINES \\ OF IRRIGATED RICE IN SÃO PAULO STATE IN 1990/91 E $1991 / 92$}

Rice cultivars and selected lines were evaluated as to their yielding potential and several agronomic traits in the State of São Paulo, Brazil, during the years 1990/91 and 1991/92. The cultivar IAC 101 and the line IAC 1085 showed a good yielding potential and stability, leaf and panicle blast resistance, dwarfness, lodging resistance, and high level of head rice after milling. The line IAC 1085 also showed earliness which make it proper for late planting. The cultivars IAC 238, IAC 242 e IAC 100 also showed reasonable yielding potential mainly in 1991/92. The cultivar IAC 4440 showed high susceptibility to leaf and panicle blast. The lines IAC 1091 and IAC 1231 showed high resistance to panicle blast and can be used in future breeding programs as gene sources for that attribute.

Index terms: rice, Oryza sativa L., yielding potential and stability of cultivars and breeding lines, blast resistance.

\section{INTRODUÇÃO}

A área cultivada com arroz no Estado de São Paulo, em 1991/92, foi de, aproximadamente, 190 mil hectares, com uma produção total de 337 mil toneladas (São Paulo, 1993). Todavia, o consumo paulista de arroz é bastante superior, havendo necessidade de grandes importações, sobretudo do Rio Grande do Sul. Aumento da produção paulista de arroz pode ser conseguido pelo incremento da área plantada, principalmente em condições irrigadas por inundação ou pela criação de novos cultivares mais produtivos e adaptados às diferentes regiões.

O programa de melhoramento do arroz do Instituto Agronômico tem procurado, mediante cruzamentos artificiais, desenvolver cultivares de porte baixo, com alto potencial produtivo e com tolerância às doenças, principalmente à brusone na fotha e na panícula. O sucesso do referido programa pode ser avaliado pelo lançamento comercial de diversos cultivares, como o IAC 435 e IAC 120 (Germeck \& Banzatto, 1972), IAC 841 e IAC 899 (Campinas, 1982), IAC 4440 e IAC 1278 (Usberti Filho et al., 1986 a, b), IAC 100 e IAC 101 (Campinas, $1991 \mathrm{a}, \mathrm{b})$.

Este trabalho objetivou avaliar o comportamento de novas linhagens oriundas do programa de melho- ramento genético do arroz do Instituto Agronômico, juntamente com cultivares recomendados para plantio no Estado de São Paulo. Tal avaliação visou à identificação das linhagens mais promissoras para multiplicação e posterior lançamento aos orizicultores ou utilização como fontes genéticas de interesse no programa de cruzamentos do Instituto Agronômico.

\section{MATERIAL E MÉTODOS}

Desenvolveram-se os experimentos nos anos agrícolas 1990/91 e 1991/92, instalando-se, no primeiro ano, sete ensaios regionais de arroz irrigado por inundação em Mococa, São José dos Campos (1 e 2), Tremembé, Taubaté, Pindamonhangaba e Roseira. Avaliaram-se os cultivares IAC 4440, IAC 238, IAC 242, IAC 100 e IAC 101 e as linhagens IAC 1081, IAC 1085, IAC 1091, IAC 1092, IAC 1093, IAC 1102, IAC 1116, IAC 1153, IAC 1156, IAC 1157 e IAC 1159, perfazendo 16 genótipos. Em 1991/92, as nove últimas linhagens foram substituídas pela IAC 1154, IAC 1158 , IAC 1160, IAC 1164, IAC 1229, IAC 1231. IAC 1233 , IAC 1235 e IAC 1242, as quais foram testadas em seis localidades (Mococa, São José dos Campos, Taubaté, Pindamonhangaba, Roseira e Pariquera-Açu). 
Adotou-se o delineamento estatístico de blocos ao acaso com quatro repetições por localidade. Todos os genótipos foram semeados em parcelas experimentais, constituídas de cinco sulcos de $5 \mathrm{~m}$ de comprimento, espaçados de $0,30 \mathrm{~m}$ entre si. A densidade de semeadura foi de 120 sementes viáveis por metro linear de sulco, equivalendo a 400 sementes por metro quadrado. Em todos os ensaios, efetuou-se uma adubação básica na dosagem de $400 \mathrm{~kg} / \mathrm{ha}$, fórmula 4-14-8, e outra em cobertura de $60 \mathrm{~kg} / \mathrm{ha}$ de nitrogênio, aplicado parceladamente aos 30 e 60 dias após a emergência das plântulas. Durante o estádio vegetativo, realizou-se o controle de plantas daninhas de acordo com a necessidade. A irrigação por inundação teve início entre 20 e 30 dias após a emergência das plântulas em todos os experimentos.

As características agronômicas avaliadas foram as seguintes:

- Produção de grãos: produção total de grãos em casca das três linhas centrais de cada parcela, transformadas em quilograma por hectare a $13 \%$ de umidade;

- Cíclo de florescimento: número de dias decorridos da emergência das plântulas até o florescimento (50\% das plantas em antese);

- Altura das plantas: distância, em $\mathrm{cm}$, do nível do solo ao ápice da panícula, medida na época da maturação;

- Acamamento: avaliação visual da quantidade de plantas acamadas, segundo escala de 1 (nenhuma planta acamada) a 9 (100\% de plantas acamadas), sugerida no Standard Evaluation System for Rice (International..., 1988);

- Rendimento de grãos inteiros: peso em \% de grãos polidos e inteiros obtidos após o beneficiamento de $100 \mathrm{~g}$ de arroz em casca em engenho de provas marca Suzuki;

- Incidência de brusone na panícula: avaliação visual da ocorrência de lesões causadas por $P$. oryzae no estádio de maturação, em condições naturais de infecção, empregando-se escala de 0 (sem sintomas) a 9 (mais de $50 \%$ de panículas com sintomas) (International..., 1988);
- Reação de brusone nas folhas: realizada em canteiros padronizados instalados em Pindamonhangaba (duas localidades) e Tremembé, conforme método sugerido por Ou (1972).

\section{RESULTADOS E DISCUSSÃO}

\section{Experimentos de 1990/91}

Os resultados de produção de grãos dos experimentos de 1990/91 constam do quadro 1. A análise conjunta da variância desses resultados indicou que houve efeitos significativos para experimentos, genótipos e interação genótipos $\mathrm{x}$ experimentos. Constam, também, do quadro 1, os valores de $F$ para genótipos e o coeficiente de variação das análises conjuntas e individuais da variância.

Pelo teste de Tukey ao nível de 5\% para a comparação das médias de produção de grãos dos genótipos, observou-se que, em Mococa, a linhagem IAC 1092 foi a mais produtiva $(7.517 \mathrm{~kg} / \mathrm{ha})$, não diferindo, porém, das linhagens IAC 1091 $(7.405 \mathrm{~kg} / \mathrm{ha})$, IAC 1085 e IAC 1157 e dos cultivares IAC 242, IAC 101 e IAC 238. A linhagem IAC 1092 também foi a que mostrou maior produção em São José dos Campos 2 e Pindamonhangaba, com produçôes de 7.512 e $8.882 \mathrm{~kg} / \mathrm{ha}$ respectivamente, embora não diferindo dos outros cinco genótipos mais produtivos do primeiro local e dos 13 melhores em Pindamonhangaba.

Nas outras quatro localidades, destacou-se o 'IAC 101', com produções de 6.487, 3.632, 8.307 e $6.915 \mathrm{~kg} / \mathrm{ha} \mathrm{em}$, respectivamente, Taubaté, Roseira, Tremembé e São José dos Campos 1. O 'IAC 101' não diferiu significativamente da linhagem IAC 1085 nas quatro localidades; dos genótipos IAC 100, IAC 242, IAC 1081, IAC $1091 \mathrm{e}$ IAC 1102 em três; do IAC 238 e IAC 1092 em duas, e das linhagens IAC 1093 e IAC 1159 em apenas uma. Destaque maior deve ser dado ao cultivar IAC 101 e à linhagem IAC 1085 nos experimentos do ano agrícola 1990/91, em função de ambos apresentarem produções médias entre os mais produtivos em todas as localidades e, consequientemente, mostrar excelente estabilidade produtiva. 


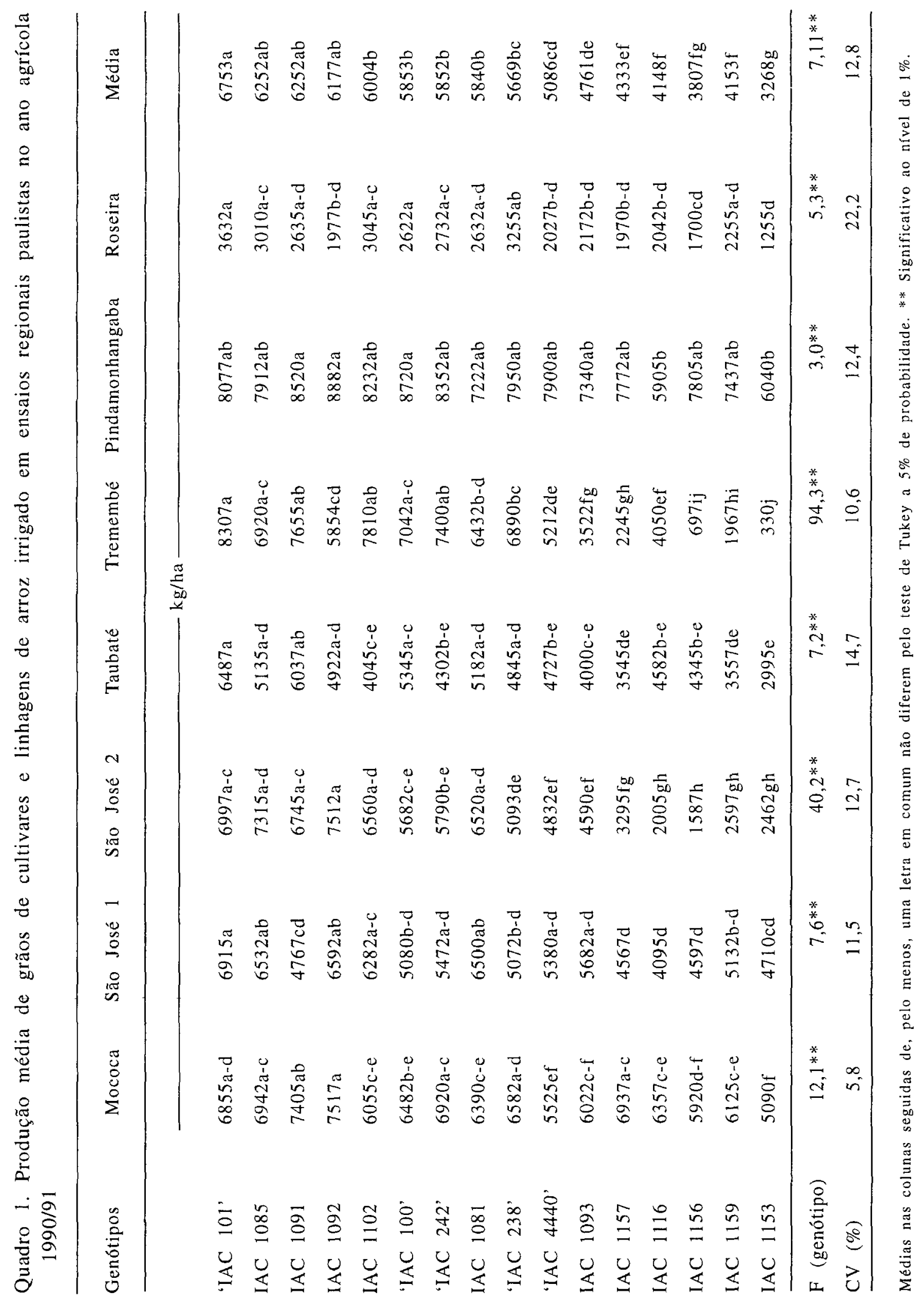




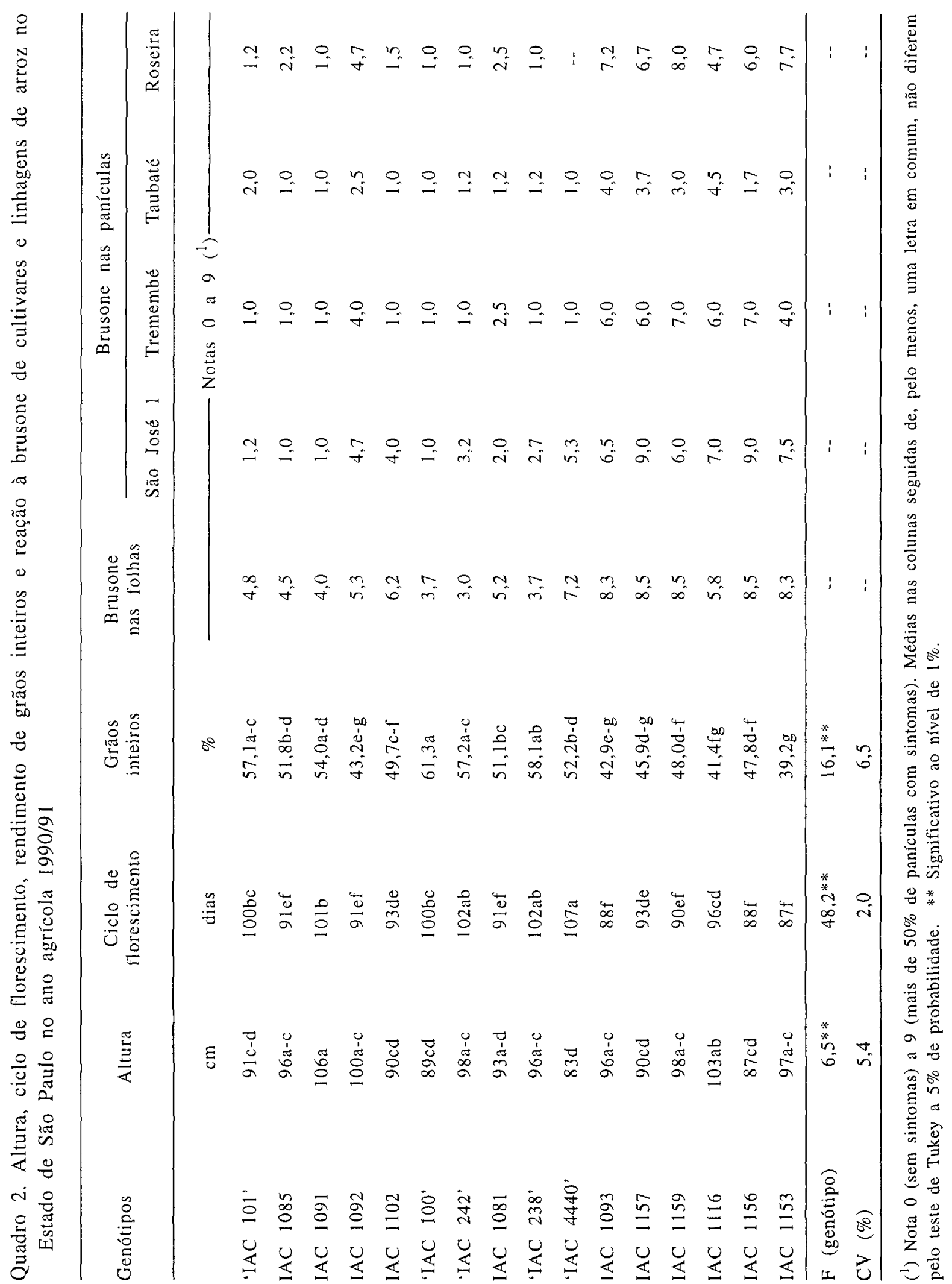


No quadro 2 , indicam-se os dados de altura de planta e ciclo de florescimento estimados apenas no ensaio da Estação Experimental de Mococa: a linhagem IAC 1091 apresentou maior altura, diferindo apenas dos genótipos IAC 101, IAC 1102 , IAC 1157, IAC 100, IAC 1156 e IAC 4440. Apesar dessas diferenças, quase todos os genótipos estudados foram considerados de porte semi-anão e apenas a linhagem IAC 1091, de porte intermediário.

Os resultados de ciclo de florescimento revelam que os cultivares IAC 4440, IAC 238 e IAC 242 foram os mais tardios, diferindo significativamente da maioria dos genótipos estudados. As linhagens IAC 1081, IAC 1085, IAC 1092, IAC 1159, IAC 1156, IAC 1093 e IAC 1153, com ciclo inferior a 91 dias, podem ser consideradas de grande interesse para o programa de melhoramento genético do IAC.

O rendimento de grãos inteiros após beneficiamento, determinado no ensaio de Tremembé, também se encontra no quadro 2. Os genótipos IAC 100 , IAC 238, IAC 242 e IAC 101, com rendimento de grãos inteiros superior a $57 \%$, mostraram melhor comportamento, diferindo das linhagens IAC 1159, IAC 1156, IAC 1157 , IAC 1092, IAC 1093, IAC 1116 e IAC 1153, com rendimento de grãos inteiros inferior a $48 \%$. A incidência de brusone na panícula foi, provavelmente, a principal causa do seu baixo rendimento.

A reação média à brusone nas folhas e seus índices de infecção nas panículas em São José dos Campos 1, Tremembé, Taubaté e Roseira constam do quadro 2. Em relação à brusone nas folhas, destacaram-se, quanto à resistência, os cultivares IAC 100, IAC 238 e IAC 242, com notas inferiores a 4,0. Os genótipos IAC 1102, IAC 4440, IAC 1093, IAC 1153, IAC 1156, IAC 1157 e IAC 1159 , com notas médias superiores a 6,0 , foram considerados altamente suscetíveis à brusone nas folhas. Quanto à brusone na panícula, os genótipos IAC 101, IAC 1085, IAC 1091, IAC 100, IAC 242 e IAC 238 foram os mais resistentes. Os genótipos IAC 1092, IAC 1081, IAC 4440 e IAC 1102 apresentaram comportamento intermediário, enquanto IAC 1116, IAC 1153, IAC 1156 , IAC 1093, IAC 1159 e IAC 1157 revelaram maior suscetibilidade à brusone na panícula.

\section{Experimentos de 1991/92}

As produções médias de grãos dos genótipos testados em 1991/92 encontram-se no quadro 3. Sua análise conjunta da variância mostrou que os efeitos de experimentos, genótipos e interação genótipos $\mathrm{x}$ experimentos, foram altamente significativos. Os efeitos de genótipos, analisados individualmente, foram altamente significativos em todos os experimentos. Pelo teste de Tukey aplicado ao nível de $5 \%$ para a comparação das médias de produção de grãos, em Mococa, não se constataram diferenças significativas entre os 13 genótipos mais produtivos. O 'IAC 101' foi o de maior produção, diferindo apenas das linhagens IAC 1158, IAC 1229 e IAC 1160.

Em Taubaté, a linhagem IAC 1085 e os cultivares IAC 101, IAC 242, IAC 100 e IAC 238 mostraram maior produção de grãos $(7.025,6.352,6.295,5.970$ e $5.690 \mathrm{~kg} / \mathrm{ha}$ respectivamente), não diferindo, de maneira significativa, entre si.

Em São José dos Campos, destacou-se a linhagem IAC 1081, com uma produção de $6.257 \mathrm{~kg} / \mathrm{ha}$, não diferindo, porém, dos genótipos IAC 101, IAC 1231, IAC 1154, IAC 4440, IAC 1229, IAC 100 e IAC 1085.

Em Pindamonhangaba e Roseira, o 'IAC 101' mostrou a maior produção de grãos $(8.737$ e 8.637 $\mathrm{kg} / \mathrm{ha}$ respectivamente), não diferindo nem dos outros 12 genótipos mais produtivos na primeira localidade nem dos cultivares IAC 238 e IAC 242, na segunda.

Em Pariquera-Açu, os 11 genótipos mais produtivos não mostraram diferenças significativas entre si, destacando-se o 'IAC 242'.

Considerando a média de todos os experimentos, destaca-se o 'IAC 101' (7.520 kg/ha), não diferindo significativamente apenas do cultivar IAC 242. O 'IAC 101' também mostrou excelente estabilidade produtiva, situando-se entre os mais produtivos em todas as localidades. Os cultivares IAC $242(7.067 \mathrm{~kg} / \mathrm{ha})$, IAC $238(6.765 \mathrm{~kg} / \mathrm{ha})$ e a linhagem IAC $1085(6.582 \mathrm{~kg} / \mathrm{ha})$ também mostraram excelente potencial produtivo. 


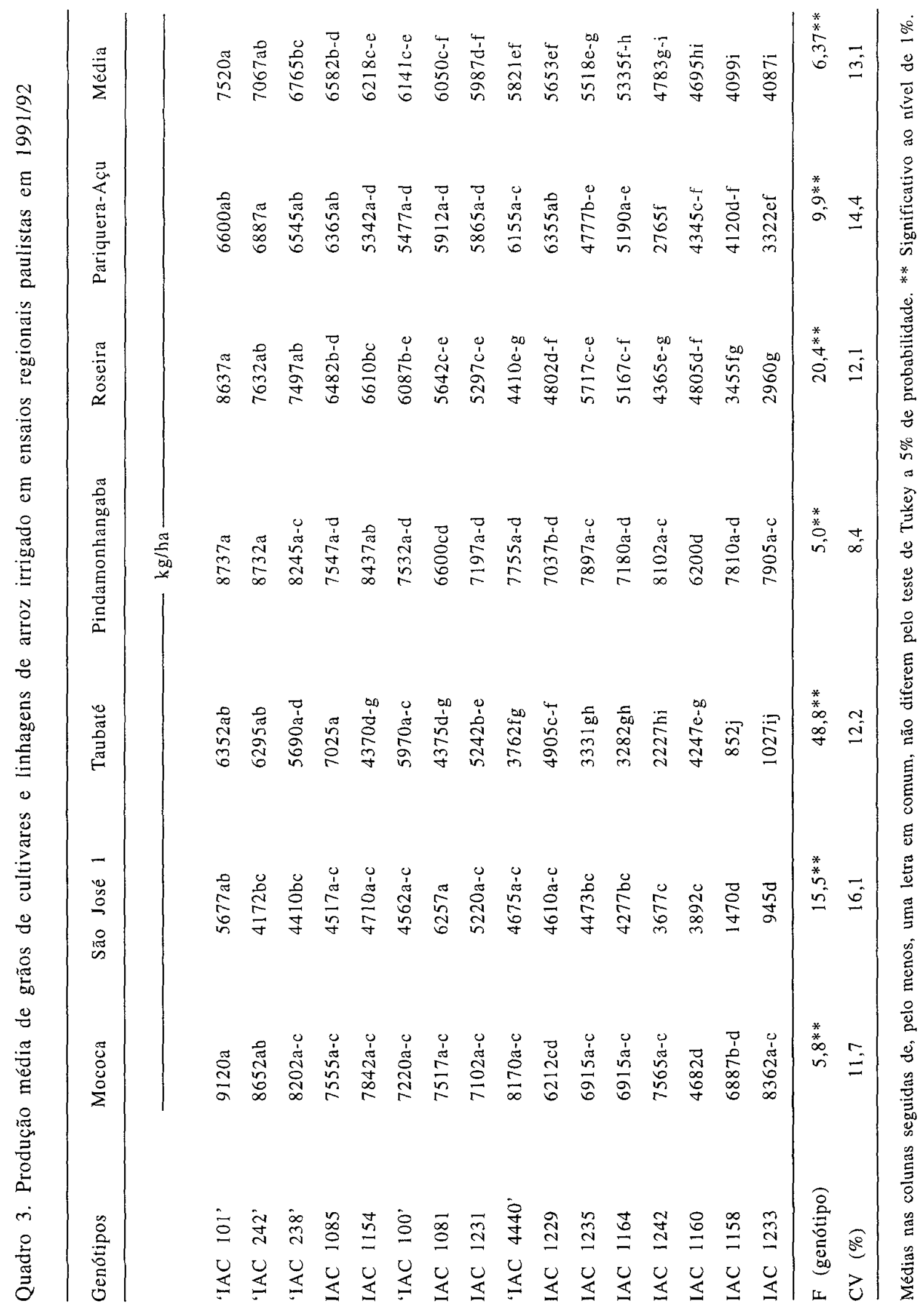




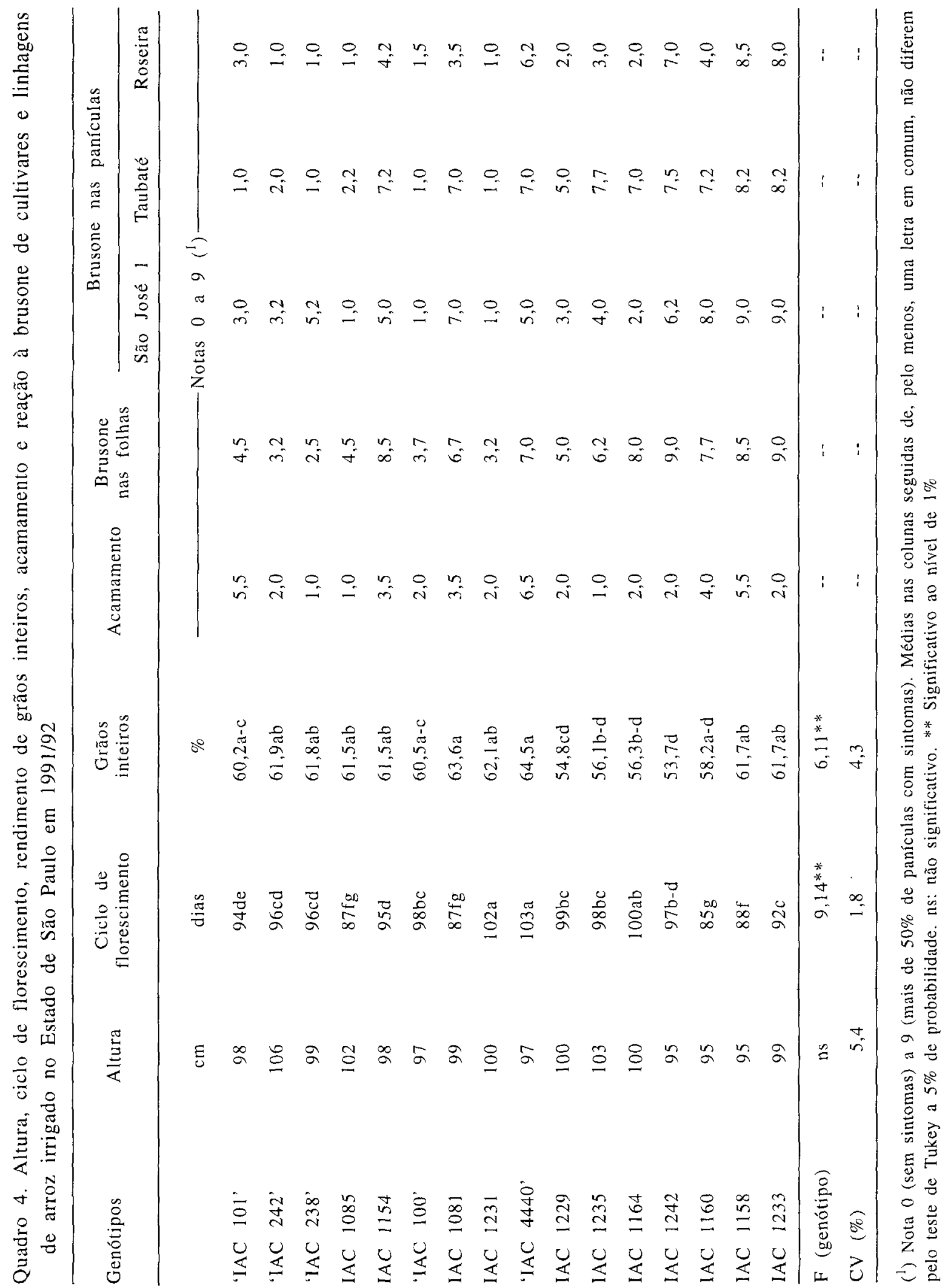


A altura das plantas dos genótipos de arroz estudados em 1991/92 foi determinada apenas nos cnsaios de Mococa e Pariquera-Açu. A análise conjunta da variância dessas observações mostrou efeitos não significativos para genótipos e para a interação genótipos $\mathrm{x}$ experimentos e significativos para experimentos. A maioria dos genótipos apresentou altura média ao redor de $100 \mathrm{~cm}$, sendo considerados, portanto, de porte baixo ou intermediário. A ocorrência de acamamento, normalmente associada ao porte de planta mais elevado, foi notada, de maneira generalizada, apenas no ensaio de Pariquera-Açu. Os genótipos IAC 238, IAC 1085 e IAC 1235 não acamaram (Quadro 4).

A análise conjunta da variância para ciclo de florescimento dos experimentos de Mococa e Pariquera-Açu mostrou efeitos significativos para genótipos, experimentos e interação genótipos $x$ experimentos. Os ciclos médios observados nessas duas localidades encontram-se no quadro 4. O 'IAC $4440^{\prime}$ e a linhagem IAC 1231 foram os mais tardios (103 e 102 dias respectivamente), enquanto as linhagens IAC 1233, IAC 1158, IAC 1085, IAC 1081 e IAC 1160 , com ciclo entre 92 e 85 dias, foram consideradas de ciclo precoce.

Após o beneficiamento dos genótipos estudados em 1991/92, estimou-se o rendimento de grãos inteiros apenas no ensaio de Mococa; seus valores médios encontram-se no quadro 4 . O cultivar IAC 4440 apresentou o melhor rendimento $(64,5 \%)$, diferindo, porém, apenas das linhagens IAC 1164 , IAC 1235, IAC 1229 e IAC 1242.

Os resultados da reação à brusone na folha e da sua incidência nas panículas nos ensaios de São José dos Campos 1, Taubaté e Roseira, encontram-se no quadro 4. Os genótipos IAC 238, IAC 242, IAC 1231 e IAC 100, com notas médias inferiores a 4,0, apresentaram melhor comportamento quanto à resistência à brusone nas folhas. Os genótipos IAC 1154, IAC 1081, IAC 4440, IAC 1235, IAC 1164, IAC 1242, IAC 1160, IAC 1158 e IAC 1233, com notas médias superiores a 6,0 , foram considerados como altamente suscetíveis. Quanto à brusone nas panículas, apenas os genótipos IAC 1231 e IAC 100 mostraram-se resistentes. Os genótipos IAC 101 , IAC 242 e IAC 1085 revelaram-se mode- radamente resistentes, enquanto os demais foram suscetíveis ou altamente suscetíveis.

\section{CONCLUSÕES}

1. O cultivar de arroz irrigado IAC 101 revelou excelente potencial e estabilidade de produção de grãos.

2. A linhagem IAC 1085 destacou-se quanto à produção de grãos, precocidade e outras características agronômicas, constituindo-se em genótipo altamente promissor.

3. O 'IAC 4440' mostrou-se altamente suscetível à brusone tanto nas folhas como nas panículas.

4. As linhagens IAC 1091 e IAC 1231 mostraram resistência à brusone da panícula, podendo servir como fontes de genes para a melhoria dessa característica em futuros programas de melhoramento genético.

\section{REFERÊNCIAS BIBLIOGRÁFICAS}

CAMPINAS. Coordenadoria de Assistência Técnica Integral. Características das cultivares de arroz recomendadas para o Estado de São Paulo. Campinas, CATI, 1982. (Fôlder)

CAMPINAS. Instituto Agronômico. IAC 100: novo cultivar de arroz irrigado para o Estado de São Paulo. Campinas, Instituto Agronômico, 1991a. (Fôlder)

CAMPINAS. Instituto Agronômico. IAC 101: novo cultivar de arroz irrigado para o Estado de São Paulo. Campinas, Instituto Agronômico, 1991b. (Fôlder)

GERMECK, E.B. \& BANZATTO, N.V. Melhoramento de arroz no Instituto Agronômico. Campinas, Instituto Agronômico, 1972. 56p. (Boletim 202)

INTERNATIONAL RICE RESEARCH INSTITUTE. Los Baños. Filipinas, Standard evaluation system for rice, $1988.54 \mathrm{p}$.

OU, S.H. Methods of evaluating varietal resistance. In: Rice Diseases. Kcw, Surrey, England, Commonwealth Mycological Institute, 1972. 368p.

SÃo PAULO. Prognóstico agrícola 92/93. Informações Econômicas, São Paulo, 23:56-64, 1993. 
USBERTI FILHO, J.A.; AZZINI, L.E.; CAMARGO, O.B.A.; SOAVE, J.; SCHMIDT, N.C.; VILLELA, O.V.; GALLO, P.B., SAKAI, M.; TISSELLI FILHO, O. \& VITTI, P. IAC 4440: novo cultivar de arroz irrigado para o Estado de São Paulo. Campinas, Instituto Agronômico, 1986a. 10p. (Boletim técnico, 107)
USBERTI FILHO, J.A.; AZZINI, L.E.; SOAVE, J.; VITTI, P.; LEITÃO, R.F.F.; PIZZINATTO, A.; VILLELA, O.V. \& GALLO, P.B. Características agronômicas e de qualidade de produto de cultivares de arroz de sequeiro e irrigado. Pesquisa Agropecuária Brasileira, Brasília, 21(12):1283-1296, 1986 b. 